\title{
The Trouble with Preservation, or, Getting Back to the Wrong Term for Wilderness Protection: A Case Study at Point Reyes National Seashore
}

\author{
LAURA A. WatT \\ University of California, Berkeley
}

\begin{abstract}
How "untrammeled" must a wilderness be at the time it is designated as such? Should the intent behind designating wilderness areas be to protect existing areas that meet the official definition, or to create new ones through management actions? This question is explored by looking at the historical evolution of the Philip Burton Wilderness Area in Point Reyes National Seashore, which gradually has been transformed from a dairy ranching landscape to an apparently pristine wilderness. In the process, the history of human habitation and use of the area has been downplayed or overlooked. This case raises questions about the interplay between considerations of ecological functioning, recreation demands, and simple aesthetics in defining managed wilderness. It also suggests that new terminology for wilderness protection that differentiates between varying degrees of previous human use could help to avoid the erasure of history from preserved natural areas.
\end{abstract}

\section{Introduction}

IN HIS 1995 ESSAY, "The Trouble with Wilderness; or, Getting Back to the Wrong Nature," William Cronon described wilderness as the product of civilization rather than the absence of it; traces of human use and history are wiped out in favor of an empty natural landscape. Wilderness is mythologized as being outside of the human sphere, but the creation of these kinds of places "reminds us just how invented, just how constructed, the American wilderness really is... a product of the very history it seeks to deny." This tendency to mythologize wilderness contributes to environmental problems, 
as it suggests the possibility of returning to some pristine natural state, like a clean slate, and posits humans as the cause of degradation but never the solution. Cronon suggests that we are "unlikely to make much progress in solving these problems if we hold up to ourselves as the mirror of nature a wilderness we ourselves cannot inhabit" (Cronon 1995, p. 83).

One literal example of creating wilderness is the case study of the Philip Burton Wilderness Area in the Point Reyes National Seashore (PRNS), just north of San Francisco in California. Established in 1976, the Point Reyes wilderness has been constructed from a historic ranching landscape, and in the process of managing and interpreting this area, the history of its human habitation and use has been downplayed or overlooked. This erasure of history is not an accident; it represents a strategic reconfiguration of the landscape to bring it closer in appearance to public and agency expectations of what a wilderness area "ought" to look like. It also masks the new uses-wilderness recreation and park management-that have replaced the old, making them appear not to be "uses" at all but passive maintenance and admiration of a timeless natural scene. Several writers recently have described how the National Park Service (NPS) has conducted this kind of cultural erasure with Native American cultures (Catton 1997, Spence 1999); the PRNS case represents the erasure of Euro-American settlement as well.

The 1964 Wilderness Act defined wilderness as "untrammeled," a landscape where "the nonhuman forces of nature are to be given free rein." Yet there are almost no places on earth that have not been trammeled at one time or another; in particular, almost all publicly owned lands in the U.S. were at one time roaded, logged, farmed, or utilized in some other way. In an effort to establish a national wilderness system, Congress accepted a less-pure definition of wilderness for purposes of designation (Woods 1998, p. 136, emphasis in original): "The Congressional and judicial rejection of the USFS's purity definition of wilderness suggested that the untrammeled character of naturalness was more forward-looking: wilderness lands were to be managed in such a way that they would 
be untrammeled and return to primeval conditions in the future." Agency management of designated wilderness is the process by which these lands become increasingly untrammeled, or at least seem to be untrammeled. The appearance of natural purity remains the ultimate goal of most management approaches, which results in erasing traces of human history.

This paper presents a case study of the Point Reyes wilderness area and highlights the importance to land managers of creating the impression of wilderness, rather than meeting any actual standards of ecological functioning, roadlessness, or isolation. It also argues that knowing the human history of the area erodes this "feeling" of wilderness; official interpretation of the area steers visitors away from noticing the extent to which Point Reyes has been trammeled. The NPS and other land management agencies could help to heal this disconnect between nature and culture by encouraging the public to understand the human history of natural areas, even while continuing to manage for wilderness values.

This paper also draws some comparisons between the preservation of wilderness and historic resources. Specifically, it suggests that the trend of glossing over cultural history stems not only from expectations associated with the term "wilderness," but also from the concept of "preservation," with its implications of protecting some preexisting, unchanging, and everlasting condition of the landscape. Because most, if not all, wildernesses have undergone some degree of human manipulation and management, perhaps a continuum of terms is needed to refer to specific levels of former use and restoration. One such continuum can be found in the historic preservation literature: historic buildings and other resources may be preserved, rehabilitated, restored, or reconstructed. If wilderness protection were not bound by the restrictive concept of preservation-if the current definition of what counts as wilderness were not so black and white, as Cronon detailed in his essay, but allowed more shades of gray-agencies could continue to manage for wilderness values while acknowledging the historic qualities of the landscape. 


\section{Historic Background}

The NPS first studied the Point Reyes peninsula as a potential park location in the 1930s, and in 1959 formally proposed the area as a National Seashore. It was not an empty landscape, though; coastal Miwok tribes had inhabited the region for centuries. Beginning in the 1830s, Mexican rancheros began grazing cattle on massive land grants. After 1850, when California became part of the U.S., several families began to develop dairies on the peninsula, drawn by the extended growing season for pasture. Litigation over the land title to the Mexican land grants resulted in ownership of the entire peninsula falling into the hands of a legal firm-Shafter, Shafter, Park, and Heydenfeldt. The Shafters soon developed a network of 32 tenant-run dairies and cattle ranches, most named for letters of the alphabet, transforming the entire Point into an ordered, fenced industry (Figure 1). Eventually the lawyers' estates sold the ranches off, usually to the resident tenant families (Livingston 1993).

The southern end of the peninsula, which now makes up the bulk of the wilderness section of the park, has steeper topography than the northern end and gets more rain, and thus is more prone to brush and forest communities. The ranches in this area were generally smaller than the northern ones, and tended to have difficulty keeping grazing lands clear of encroaching brush. A number of these dairies were abandoned during the 1930s or converted to beef ranches and used for hunting and recreation activities. Other uses of the land, such as mercury mines and military installations during World War II, mixed in with the ranching landscape. Still, by the time the peninsula was established as a national seashore in 1962, the Bear Valley (W), New Albion (R), and Laguna (T) ranches all remained actively in use, and the Glenbrook Ranch had just recently ceased dairy operations. Logging activity was taking place on the Lake Ranch, and the Christ Church of Golden Rule had converted the South End Ranch into a religious community. Paved roads led to the New Albion, Wildcat, and Lake ranches. The owner of old Muddy Hollow Ranch had subdivided and platted the property for a housing development, with roughly 20 homes and a paved road along the Limantour Spit. The area was in no way untrammeled or 


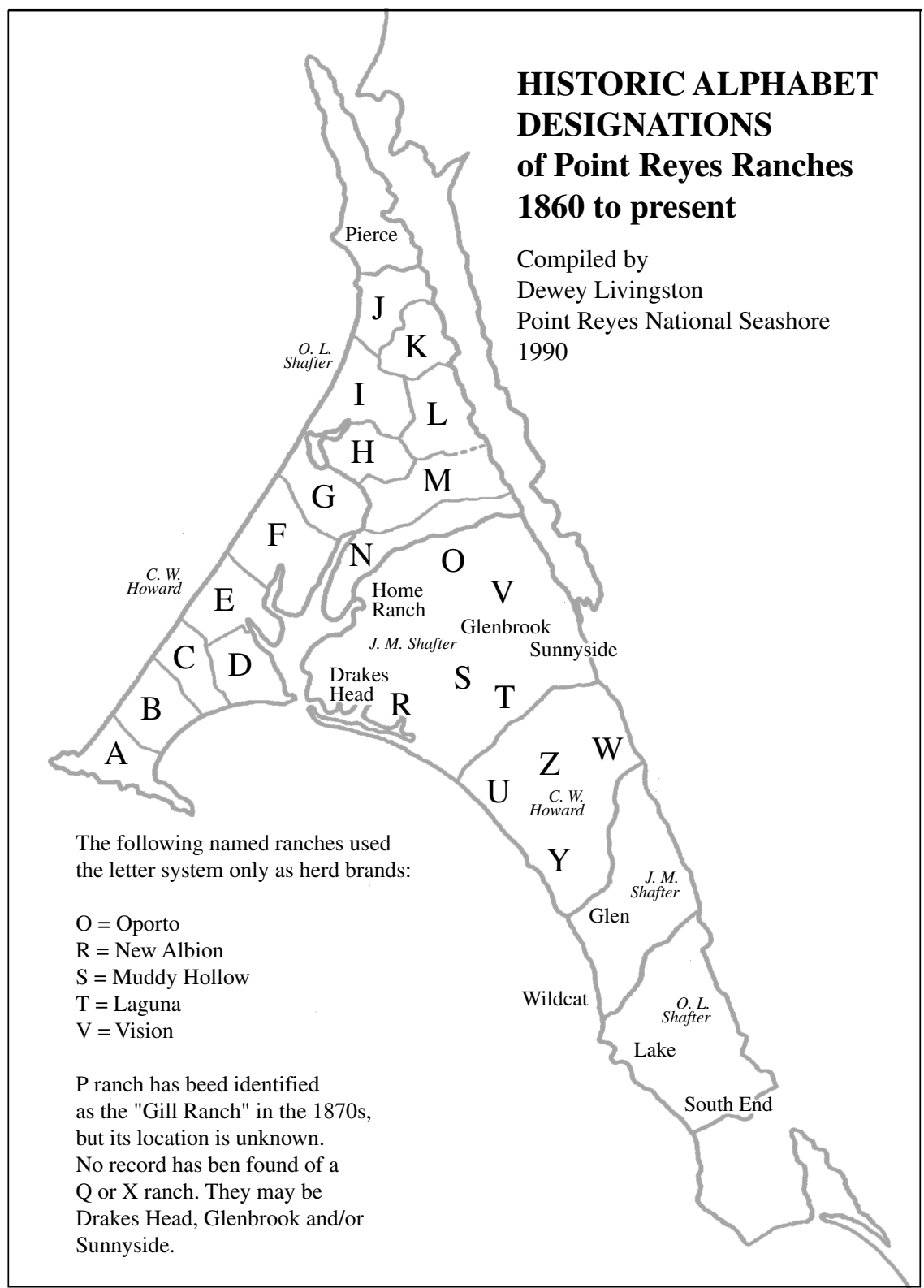

Figure 1. Point Reyes Ranches. 
pristine, and evidence of human use was both extensive and prominent throughout the peninsula.

\section{Erasing Human History}

The NPS proposed Point Reyes as a National Seashore, specifically not a National Park, with a primary purpose of providing for public recreation. ${ }^{1}$ During the 1961 Senate hearings, sponsoring Congressman Clem Miller stressed in his testimony, and was later echoed in a statement from the National Parks Association (NPA), the "very important" distinction between "national primeval parks" and Point Reyes, a national seashore close to an urban area. The NPA even argued that "this provision for a pastoral area within the park, preserving present uses, is highly desirable. In fact, the combination of dairy country and wild natural shoreland is part of the charm of Point Reyes, and we think the combination ought to be preserved" (U.S. Congress 1961, p. 70). The Wilderness Society also suggested that protecting Point Reyes "for its maximum values in recreation" would help relieve growing recreation pressure on parks and wilderness areas in the Sierras (U.S. Congress 1961, p. 168). The legislation included clear congressional intent that ranching should remain within the park, setting up a special "pastoral zone" which would stay in private ownership (U.S. Congress 1960, p. 139).

In contrast, the southern district of the peninsula was designated the "public use area," and extensive developments for recreation were planned, including a four-lane federal parkway running throughout the peninsula and developments for car camping, boating, etc. Because of the slow pace and high expense of land acquisition efforts during the 1960s, none of these plans were implemented.

Despite their historical and current predominance at Point Reyes, the dairies were relatively invisible to NPS planners and managers, who focused instead on the natural character of the landscape. The first NPS recreation survey of the area done in 1935 mentions the presence of "ranch holdings" on the peninsula, but not specifically the dairy industry as a commercial development. NPS Director Conrad Wirth opened his testimony at Senate hearings in 1960 with reference to how the area had been "left so unaltered by the hand of man" (p. 6). The following year, cosponsoring Congressmen Clair 
Engle and Miller commented that little had changed at Point Reyes since Sir Francis Drake allegedly landed there in 1579. From the beginning, the NPS management has emphasized the supposed pristine quality of the natural resources, overlooking the 150 years of extensive modifications of the landscape for ranching and other uses.

Almost immediately after the Seashore's establishment, NPS staff began eliminating traces of former human habitations, particularly from the "public use" section of the Seashore. Deteriorated ranch buildings were removed at a number of ranch sites throughout the park, usually leaving no obvious evidence of previous settlement and use. Approximately 60 structures were burned at the former Christ Church of the Golden Rule community on the old South End/ Palomarin Ranch site. Most of the houses built as part of the Drake's Beach Estates subdivision on Limantour Spit were also burned after condemning the land, even though most were no more than a year or two old. The Lake Ranch property was condemned in 1971 and all the old ranch buildings were removed; similar demolitions took place at the New Albion (R) Ranch. All four of the current hike-in campgrounds in the park are former ranch sites, yet other than the occasional remaining eucalyptus or cypress tree, there is no indication at any of these sites of their historic use. Staff removed pavement from primary roads in the southern region and converted them to trails, and abandoned many secondary roads to become overgrown or to erode away.

Removal of buildings from parklands is a fairly common practice for the NPS, so none of this is particularly surprising. For example, at Shenandoah National Park in Virginia in the 1930s, the NPS evicted a large number of residents from within the park boundaries and tore down nearly all of their farms, clearing the way for a new landscape narrative of pristine wilderness (Reich 2000). This pattern highlights the degree to which preservation of natural areas, whether formally designated wilderness or not, eliminates human history from the area, as if nature and culture were completely incompatible. This adds some nuance to Cronon's criticism, in that the mythology of wilderness as empty of human influence reaches farther than places actually designated as wilderness; it affects all natural areas subjected to formal preservation. This only 
perpetuates the false sense of separation between people and nature, making it harder to understand the ways in which nature and culture are inextricably linked and interdependent.

\section{Establishment of the PRNS Wilderness Area}

Once the majority of the peninsula was in public ownership, NPS staff began studying the desirability of establishing a wilderness area at PRNS, according to congressional mandate that all federal agencies scrutinize their holdings for potential wilderness designations. Described as a "backyard urban wilderness," the preliminary proposal emphasized the contrast between the increasingly congested Bay Area and the "primitive, untouched" qualities of Point Reyes (PRNS 1971, p. 5). Interestingly, public demand drove wilderness designation much more than the NPS itself; PRNS staff originally recommended the designation of 5,150 acres as wilderness, but increased it to 10,600 acres in 1972 after public comment strongly favored a larger wilderness area.

As had been the case with the original Seashore proposal, the NPS ignored historical uses of the Point Reyes landscape with regard to possible wilderness designations. The environmental impact statement for the proposal included no mention of the old ranch sites within the proposed wilderness area. The by-then unpaved ranch roads that made up the trail system were cited as "the only visible remnants of man's past activities in the area"-despite the acknowledged presence of 50 miles of fence lines, some World War II-era bunkers, several old borrow pits, and a few old ranch dumps that were "being removed or obliterated." However, the proposal described the remaining operating ranches outside the wilderness zone with emphasis on the environmental damage they caused, with references to "scars" from development and use (PRNS 1974, pp. 14-15, 25). Characterizing the non-wilderness area ranches as destructive to the natural environment forms a stark contrast to the total invisibility of all ranches when the Seashore itself was actually proposed, when the entire peninsula was described as virtually untouched and pristine.

Public interest in wilderness designation eventually pushed the NPS to recommend an even larger acreage, adding 14,880 more acres 
to the original proposal, bringing the total to 25,480 acres. The bills proposed to Congress cited wilderness designation as the highest value for public use, education, and enjoyment of Point Reyes, and suggested that these could be "lost or degraded by management policies designed for other, less natural areas of our National Park System." Point Reyes was contrasted to neighboring Golden Gate National Recreation Area (GGNRA) as being more wild and natural, thus deserving of the wilderness designation. None of those testifying at the hearings mentioned anything about the area's former history as a heavily ranched landscape. One senator questioned the appropriateness of calling areas with so many human-made encumbrances and nonconforming uses "wilderness," suggesting that the original intent of the Wilderness Act had eroded to the point where any place, even downtown Manhattan, could be designated (U.S. Congress 1976, p. 308-9). Yet his concerns were not shared by the other representatives, the NPS, or the public.

In 1976, Congress passed a wilderness designation for 25,370 acres, with "potential wilderness" additions of 8003 acres $^{2}$ (see Figure 2). Congress also amended PRNS legislation to add that the Secretary must administer the entire park "without impairment of its natural values, in a manner that provides for such recreational, educational, historic preservation, interpretation, and scientific research opportunities that are consistent with, based upon, and supportive of the maximum protection, restoration, and preservation of the natural environment within the area." The 1980 General Management Plan referred to PRNS as the "wilderness unit" and GGNRA as the "recreation unit" of the Bay Area national parklands, even though both were originally established as recreation areas. This management emphasis has erased the previous human use of the wilderness area and replaced it with an ahistorical, "natural" landscape.

\section{The "Feeling" of Wilderness}

The case of Point Reyes highlights the importance of visual impressions of the landscape in determining wilderness status. In many cases, these visual aspects seem to matter more in wilderness policy than actual previous uses, roads, or ecological functioning of the 


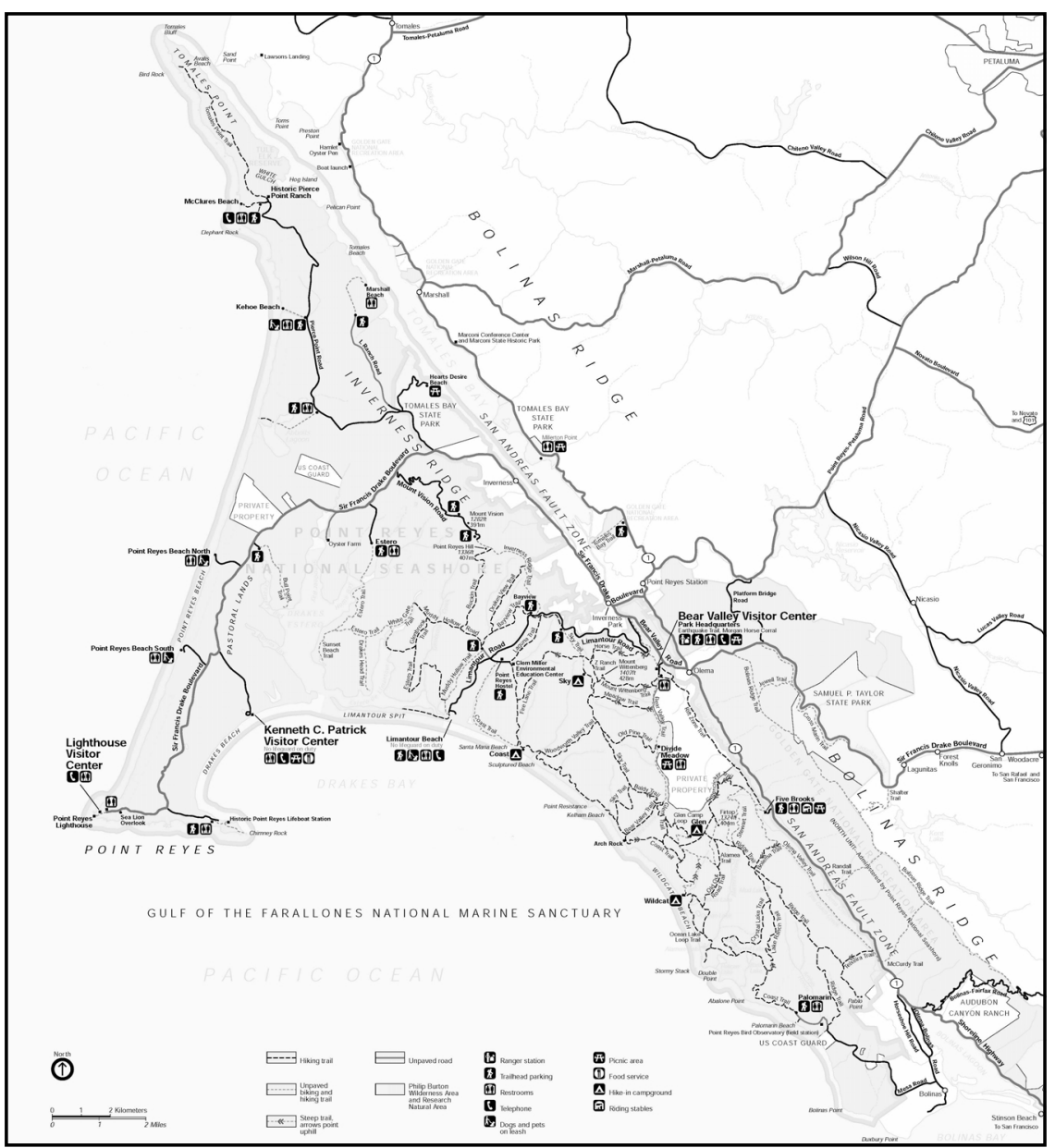

Figure 2. Point Reyes National Seashore (source: http://www.nps.gov/pore/ ppmaps / poremap1\%2Epdf).

area. This conclusion is echoed in recent work by Nemeth and Keirsey (1999), who found that riverway cleanup programs are often based more on aesthetics than on ecology. The emphasis on the perceptual nature of wilderness is stressed by the 1964 Act itself: Section 2(c)(I) says wilderness "generally appears to have been affected primarily by the forces of nature, with the imprint of man's work substantially unnoticeable" (emphasis added). Mark Woods' 
(1998, p. 140) analysis of the legal history of wilderness preservation suggests that the relative naturalness of an area is based almost exclusively on this kind of perception. What matters is not the actual degree of naturalness, solitude, or isolation; it is the experience that determines whether an area can be considered wilderness or not.

The Point Reyes wilderness area is not a single contiguous unit but is scattered in pieces across the peninsula, including approximately 2,600 acres isolated at the end of Tomales Point, small narrow strips of the Point Reyes Beach, and most of Drake's Estero but not the lands that surround it. The bulk of the wilderness is in the southern section of the Seashore but is bisected by the Limantour road and several access corridors, which have been "cherry-stemmed" out of the designated wilderness, cut extensively across it. The entire wilderness area was at one time or another used for dairy ranching, and much of it was also logged. Many buildings and paved roads were removed only a few years prior to wilderness designation; natural processes had not yet had much time to exert their force toward reducing the imprint of human history.

Yet none of these facts detracted from the asserted "wilderness character" of the area. A number of letters of comment on the Point Reyes wilderness recommendation and final environmental assessment even urged the NPS to clear additional lands of existing ranching operations so that they could be added to the wilderness area-or at least designate them as "potential" wilderness, to be upgraded in status once existing use leases expired. The California Resources Agency's letter (PRNS 1972, p. 31) suggested, "The nonownership of land or the presence of existing developments should not be a deterrent to the establishment of meaningful wilderness. Land can be acquired and developments can be obliterated." Apparently creating an impression of wilderness took precedence even over Congressionally sanctioned uses for the landscape.

As suggested by the Wilderness Act, the feeling of wilderness seems to stem primarily from the visual experience of the landscape. At the 1976 PRNS wilderness hearings, the question arose of whether to include Point Reyes Beach in the designated area. NPS staff argued that it should not be included because of its accessibility to 
cars; on warm days, many visitors leave their cars in nearby parking lots while they use the beach. In contrast, the Sierra Club representative testified that the Beach could count as a wilderness experience as long as people walked a short distance away from the parking lots, as they would not be able to see any developments or grazing lands. He argued (U.S. Congress 1976, p. 330), "In my own personal opinion many parts of this wild beach have some of the wildest views I've ever seen, since you're faced with the wild, very violent surf and beachlands behind you. You really do not have the feeling of being close to civilization along most stretches of the Point Reyes beach." The actual proximity of the beach to parking lots and several large dairies did not matter; the restricted view was enough to warrant wilderness protection.

Recently the areas listed as "potential" wilderness have received full wilderness status, based on NPS actions such as the removal of utility lines through Muddy Hollow. The electrical lines are still there, but they have been rerouted underground, following the 1995 Mount Vision fire. Yet the physical presence of the lines is less important than their appearance. Without the lines visible across the landscape, visitors are not reminded of the actual overlay of civilization on the landscape; they can pretend they are in a pristine, isolated wilderness untroubled by such imprints of man.

\section{The Effect of Knowledge}

In order to preserve the impression of wilderness, the NPS minimizes availability of information about the actual human history. Historian Roderick Nash (1982, p. 384) has asserted that wilderness is "ultimately a feeling about a place, a state of mind, that varies from person to person...." If the public expectation of wilderness is that it is pristine and untouched by humans, knowing the degree to which the landscape was previously trammeled apparently can erode this "feeling" of wilderness. PRNS staff limits public knowledge by offering few interpretive materials that identify the human history of the area.

Interpretation plays a key role in shaping visitors' perceptions of the Seashore, by focusing attention on certain aspects of the area's history and resources. Current interpretative materials at PRNS call 
attention primarily to natural resources. Exhibits at the main visitor center at Bear Valley are overwhelmingly predominated by presentations on Point Reyes geology, ecology, and wildlife. All human history is relegated to one corner of the exhibit area, with panels on the Coast Miwok, early European exploration of the coast, and the ranching history. There is no mention of other agricultural uses of the land, nor the old hunting lodges that used to be scattered across the peninsula, the current ranching and oyster operations, nor the buildings that have been removed from the landscape. These cultural uses of the land have been left out of official PRNS history entirely. Similarly, the visitor center at Drake's Beach has exhibits only on marine ecology and Sir Francis Drake. In addition to visitor center exhibits, roadside pullout interpretive signs provide extensive information about the natural landscape and comparatively little about cultural or historic landscape.

Early discussions of historic resources in the Seashore focused intensely on the possible Drake legacy, omitting the dairies, Miwok, radio and military history, and other agricultural uses almost entirely. A preliminary draft of a Historical Resource Management Plan written in May 1968 identified the main historic theme for PRNS as "Early Explorations," with Native American populations and early American settlement as subthemes. This draft plan recommended that a formal historical structures report be done "to ascertain whether or not Point Reyes has any Historical Structures, beyond the Lighthouse and the Olema Lime Kilns." As late as 1980, the official PRNS Historic Resource Study recognized only two ranchesHome and Pierce-as qualifying for nomination to the National Register. The numerous other buildings dotted across the landscape were simply not considered part of "history."

In 1989, in response to many visitor inquiries over the presence of ranches inside the park, the PRNS superintendent posted official "historic ranch" signs by some of the ranches. Yet none of the former ranch sites outside of the pastoral zone received signs-not even $W$ Ranch at Bear Valley, where old ranch buildings are now used adaptively as the Administration Headquarters, nor the former Laguna (T) Ranch, which is now used as an Environmental Education Center. There is no indication at any of the four hike-in campgrounds 
that they were once dairies. Because of these discrepancies in how they were allotted, the official signs tell an incomplete story, erasing the previous existence of ranches in the wilderness area from its public history. ${ }^{3}$

By downplaying or omitting human history from interpretive materials at Point Reyes, NPS staff shape the expectations of visitors. Limiting the amount of information about historic uses of the landscape, particularly in the wilderness area, better allows visitors to experience the wilderness qualities without noticing any prior human intrusions or imprints. However, this omission distorts public understanding of the area's past, perpetuating the myth of wilderness as ahistorical and purified of all traces of civilization.

\section{Concluding Thoughts on Natural vs. Historic Preservation}

In the field of historic preservation, there has long been a pejorative association with reconstructions of the past. David Lowenthal (1985, p. 411) links this sentiment back to the 19th century, when writers such as John Ruskin condemned historic restoration as "a fraudulent modern contrivance." Constructed history exhibits such as Colonial Williamsburg have been criticized for their selective representation of the past, which affects public understanding. Arnold Alanen and Robert Melnick (2000, p. 7) recently noted: “This cleansing of history-actually a form of landscape scrubbing-often has served to deny future generations opportunities for new discoveries and interpretations." The National Register of Historic Places requires that certain criteria for historic integrity and authenticity be met before historic resources can be determined eligible for listing. The NPS itself deliberately avoids involvement with historic reconstruction projects.

The case of the Point Reyes wilderness area raises the question, why such a double standard? The wilderness area is an artificially created and managed setting of pristine-ness, disregarding the actual history of the place. Why do we tolerate the revision of history under these circumstances? The problems of historic authenticity do not enter in to the discussion, because the mythological view of wilderness has already placed it so far outside the human realm. As Cronon (1995, p. 79) suggests, wilderness represents a "flight from 
history," erasing all traces of that from which it sprang. In order to bring the Point Reyes wilderness into line with this ideal, NPS staff have strategically downplayed, both through management and interpretation, the extent to which the landscape has been trammeled. This process disguises the fact that even when an area is designated as wilderness, it is still subject to human use and "trammeling." It is simply being used for a different purpose, and by different people; the ahistorical quality of wilderness masks the imprints that recreation and park management leave behind.

A possible way to begin counteracting this myth of wilderness is to refer to specific types of wilderness, according to the degree to which they have been inhabited and used in the past and then manipulated to take on a more wilderness-like appearance. The historic preservation field has such a continuum, in the form of standards for treatment of historic properties (Weeks and Grimmer 1995): "Preservation" involves retention of the greatest amount of historical fabric; "rehabilitation" allows some alteration of the resource to accommodate new uses while maintaining historic character; "restoration" manipulates the resource to depict a particular period of its history; and "reconstruction" recreates a resource with new materials. Similarly, certain kinds of ecological protection projects use the same terminology, such as constructed or restored wetlands, and one author recently suggested a classification system for heritage landscapes, with six types ranging from "passively preserved" to "entirely imagined" (Francaviglia 2000). Applying these kinds of terms to wilderness areas could help avoid the effect of denying the area's human history. For example, at Point Reyes, the hike-in camps could be referred to as "restored former ranch lands," and the Muddy Hollow area as a "rehabilitated wilderness."

The tendency of wilderness management-and most natural resource preservation in general-to eliminate human history from the landscape makes for bad public policy. It negates our relationship with the land and creates an unrealistic separation between nature and culture. Cronon (1995, p. 85) writes, "The wilderness dualism tends to cast any use as $a b$-use, and thereby denies us a middle ground in which responsible use and nonuse might attain a kind of balanced, sustainable relationship." This separation can be 
seen in the case of the Point Reyes wilderness area, where 150 years of ranching history have all but disappeared from the landscape, and from the public's conception of the Seashore. However, utilizing a more nuanced range of wilderness protection that recognizes differing degrees of historic use, intervention, and managementsuch as the continuum of terms used in historic preservation-would be an excellent step toward solving this conundrum. By doing so, the NPS and other land agencies could contribute to better public understanding of both history and wilderness by being more straightforward about the past uses of lands now managed as wilderness, such as at Point Reyes.

\section{Literature Cited}

Alanen, Arnold, and Robert Z. Melnick. 2000. "Introduction: Why Preserve Cultural Landscapes?" in Preserving Cultural Landscapes in America, Arnold Alanen and Z. Melnick, eds. Baltimore: Johns Hopkins University Press.

Catton, Theodore. 1997. Inhabited Wilderness: Indians, Eskimos, and the National Parks in Alaska. Albuquerque: University of New Mexico Press.

Cronon, William. 1995. “The Trouble with Wilderness; or, Getting Back to the Wrong Nature," in Uncommon Ground: Toward Reinventing Nature, William Cronon, ed. New York: W. W. Norton \& Company.

Francaviglia, Richard V. 2000. "Selling Heritage Landscapes," in Preserving Cultural Landscapes in America, Arnold R. Alanen and Robert Z. Melnick, eds., pp. 44-69. Baltimore: Johns Hopkins University Press.

Livingston, Dewey. 1993. Ranching on the Point Reyes Peninsula: A History of the Dairy and Beef Ranches Within Point Reyes National Seashore, 1834-1992, Historic Resource Study. Point Reyes Station, CA: National Park Service.

Lowenthal, David. 1985. The Past is a Foreign Country. Cambridge: Cambridge University Press.

Nash, Roderick. 1982. Wilderness and the American Mind, third edition. New Haven: Yale University Press.

Nemeth, David J., and Deborah J. Keirsey. 1999. "Elaboration on the Nature of Woody Debris: An Ethical Snag in the Aesthetic Justification for Organized River Cleanup." APCG Yearbook 61:86107. 
PRNS (Point Reyes National Seashore). 1971. PRNS Wilderness Study.

Point Reyes Station, CA: National Park Service.

- 1972. PRNS Wilderness Recommendation. Point Reyes Station, CA:

National Park Service.

- 1974. Final Environmental Statement for Proposed PRNS Wilderness. Point Reyes Station, CA: National Park Service.

Reich, Justin. 2000. "Re-Creating the Wilderness: Shaping Narratives and Landscapes in Shenandoah National Park." Environmental History 6(1):95-117.

Spence, Mark David. 1999. Dispossessing the Wilderness: Indian Removal and the Making of the National Parks. New York: Oxford University Press.

U.S. Congress, Senate. 1960. Hearings on Establishing the Point Reyes National Seashore. Committee on Interior and Insular Affairs, Subcommittee on Public Lands, 86th Congress, Second Session.

-1961. Hearings on Establishing the Point Reyes National Seashore. Committee on Interior and Insular Affairs, Subcommittee on Public Lands, 87th Congress, First Session.

-1976. Hearings on Designating Certain Lands in the Point Reyes National Seashore As Wilderness. Committee on Interior and Insular Affairs, Subcommittee on Parks and Recreation, 94th Congress, Second Session.

Weeks, Kay D., and Anne E. Grimmer. 1995. The Secretary of the Interior's Standards for the Treatment of Historic Properties: With Guidelines for Preserving, Rehabilitating, Restoring and Reconstructing Historic Buildings. Washington, D.C.: U.S. Department. of the Interior, National Park Service, Cultural Resources Stewardship and Partnerships, Heritage Preservation Services.

Woods, Mark. 1998. "Federal Wilderness Preservation in the United States: The Preservation of Wilderness?" in The Great New Wilderness Debate, J. Baird Callicott and Michael P. Nelson, eds. Athens: University of Georgia Press.

\section{Notes}

${ }^{1}$ The National Park System has a multiplicity of designations for different park units, including national parks, monuments, battlefields, seashores, historic sites, and so on. National parks are generally the largest and most exclusively natural areas; national recreation areas and national seashores generally allow more permissive development and use. 
2 Public Law 94-544. In the NPS, areas with current incompatible uses can be given a "potential" wilderness designation, meaning that if the nonconforming uses are eliminated, the NPS can then administratively add those acres to the designated wilderness area.

${ }^{3}$ It is important to note that in its official references to the stilloperating ranches within the Seashore, the NPS primarily uses the old Shafter alphabet names, rather than current family names. However, Shafter ranches outside of the pastoral zone, if they are referred to as ranches at all, retain their non-alphabet names (i.e., Bear Valley vs. W, Laguna vs. T, etc.). Having place-based rather than family names, these sites become less and less linked to their past history as ranches, so that many people now do not know that they once were dairies. When asked why none of the former ranch sites that are now walk-in campgrounds have signs, the Chief of Interpretation referred to restrictions on interpretive signage in wilderness areas (personal communication, 3/28/00). However, there are interpretive signs about the tule elk on Tomales Point, which is also designated wilderness. 